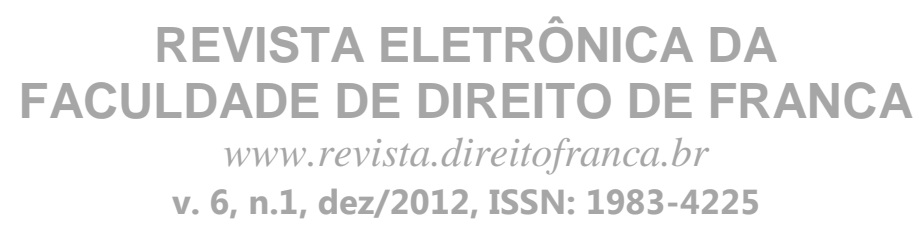

\title{
A CONSTITUIÇÃO PARA PESSOAS COM DEFICIÊNCIA: APLICAÇÃO QUE CAMINHA A PASSOS LENTOS
}

\author{
João Manoel Quirino Tristão \\ http://buscatextual.cnpq.br/buscatextual/visualizacv.do?id=K4362821H3
}

\begin{abstract}
Resumo: Estamos conscientes de que não mais é o limite individual que determina a deficiência, mas sim as barreiras existentes nos espaços, nos serviços, no transporte e na informação. Segundo o IBGE, em 2010, 45,6 milhões de pessoas possuem algum tipo de deficiência. Isto nos traduz a clara ideia de que não fossem os óbices, $24 \%$ da população brasileira poderia contribuir para que o Brasil se tornasse um país mais rico, mais forte e mais solidário. Por certo que todas as limitações existentes em nossa cidade, não obstante frear todo o desenvolvimento regional - e porque não nacional - cerceia uma óptica ainda mais exuberante: um direito constitucional. Em verdade, a cidade de Franca está em notória expansão econômica, mas devemos nos ater ao cuidado de não sobrepor os valores econômicos em detrimento aos valores sociais, sobretudo porque as pessoas com deficiência possuem quaisquer direitos inerentes à pessoa humana, compreendendo que cada obstáculo tem a sua relevância e que a dor do próximo é para ele a maior de todas. No presente artigo, destarte, dentre todo o universo de direitos, elucidaremos o direito ao trabalho e o direito ao transporte, ressaltando as falhas e problemáticas ao qual somos submetidos e que coexistem com toda a negligência na cidade de Franca, dando um enfoque sob a óptica legal, sem prejuízo da instrumentalidade e cautela que o tema imprescinde.
\end{abstract}

Palavras-Chave: Direito Constitucional, Limite individual, Pessoas com Deficiência, Aplicação das Leis destinadas à inclusão e acessibilidade das Pessoas com Deficiência.

\section{The Constitution for disabled People: a slow pace application}

\begin{abstract}
We are aware that it is not the individual limit that determines the disability, but the existing barriers in the spaces, services, transportation and information. According to the IBGE, in 2010, 45.6 million people have some sort of disability. This translates the clear idea of if there weren't any obstacles, $24 \%$ of the population could contribute to make Brazil a richer, stronger and more united country. It is certain that all existing limitations in our city, despite braking all regional development - as well as national - restrict a more exuberant optics: a constitutional right. In fact, the city of Franca is in notorious economic expansion, but we must be careful not to overlap the economic values over social values, mostly because disabled people have any rights inherent to the human person, understanding that each obstacle has its relevance and that the pain of others is for him the biggest of all. Thus, this paper elucidates, among the entire universe of rights, the right of working and the right of transportation, highlighting the flaws and problems to which we are subjected and which coexist with all the negligence in the city of Franca, under legal optics focus, notwithstanding the instrumentality and caution that the theme demands.
\end{abstract}




\section{REVISTA ELETRÔNICA DA \\ FACULDADE DE DIREITO DE FRANCA \\ www.revista.direitofranca.br \\ v. 6, n.1, dez/2012, ISSN: 1983-4225}

Keywords: constitutional law, individual limit, disabled people, law application for inclusion and accessibility for disabled people.

\section{INTRODUÇÃO}

A comunidade precisa compreender que, quando um de seus membros nasce com diferenças, todos os demais membros devem assumir juntos o compromisso de construir um ambiente inclusivo. ${ }^{1}$

O presente artigo tem o intuito de demonstrar, legal e juridicamente, as falhas na aplicação das leis destinadas a inclusão e acessibilidade das pessoas com deficiência no tocante ao seu direito ao trabalho e o seu direito ao transporte.

É relevante frisar que tal tema não só é valioso sob a óptica social, como também sob a óptica acadêmica. Ou seja, é inigualável a utilidade de um tema de tamanha projeção e inimitável repercussão, haja vista que somente estudando comportamentos negligentes é que conseguiremos tomar as devidas e necessárias providências. Ressalte-se que o descrédito só traria conflitos e consequencias desgastantes a todo o nosso viver, fazendo com que o problema não seja, de fato, solucionado e nem sequer exercido da maneira correta e plena, ou pelo menos, não da forma esperada ou esmerada como se preconiza na atualidade.

Norteados por esta visão, a tentativa foi no sentido de elaborar um estudo essencialmente prático, sem deixar de lado, contudo, a visão jurídica do assunto em espeque, abordando, a par de nossa Constituição Federal, outros mandamentos de vital importância para a compreensão do mesmo.

\section{DO DIREITO AO TRABALHO E A RESERVA DE VAGAS}

\footnotetext{
${ }^{1}$ Rinaldo Correr. Deficiência e Inclusão Social: construindo uma nova sociedade, p. 29.
} 


\section{REVISTA ELETRÔNICA DA \\ FACULDADE DE DIREITO DE FRANCA \\ www.revista.direitofranca.br \\ v. 6, n.1, dez/2012, ISSN: 1983-4225}

Art. $2^{\mathbf{0}}$. Lei 7.853/89. Ao Poder Público e seus órgãos cabe assegurar às pessoas portadoras de deficiência o pleno exercício de seus direitos básicos, inclusive dos direitos à educação, à saúde, ao trabalho, ao lazer, à previdência social, ao amparo à infância e à maternidade, e de outros que, decorrentes da Constituição e das leis, propiciem seu bem-estar pessoal, social e econômico.

O desenvolvimento da preocupação com os direitos das pessoas com deficiência elencou duas grandes consequências. A primeira e mais evidente foi assegurar o cumprimento de todos os direitos-deveres destas pessoas, inserindo-as na sociedade e em todos os seus eixos, revitalizando-as.

Por conseguinte, sob a óptica da Justiça Social, mas não menos importante, cumpre salientar que quando se contribui para que todos sejam produtivos, o resultado final cresce, fazendo com que cada cidadão usufrua de uma sociedade mais rica, mais justa e menos ociosa.

Outrossim, passou-se a idealizar que as pessoas com deficiência, desde que as suas atribuições sejam compatíveis com a deficiência de que são portadoras, são capazes de exercer com absoluta perfeição as atribuições lhes postas, fortalecendo ainda mais o país no plano econômico-social e permitindo que as pessoas tenham consciência de que produtos, serviços e espaços - como instrumentos da democracia - são para todos, nos moldes do Artigo XXIII da Declaração Universal dos Direitos Humanos:

1. Toda pessoa tem direito ao trabalho, à livre escolha de emprego, a condições justas e favoráveis de trabalho e à proteção contra o desemprego.

2. Toda pessoa, sem qualquer distinção, tem direito a igual remuneração por igual trabalho.

3. Toda pessoa que trabalhe tem direito a uma remuneração justa e satisfatória, que lhe assegure, assim como à sua família, uma existência compatível com a dignidade humana, e a que se acrescentarão, se necessário, outros meio de proteção social. 


\section{REVISTA ELETRÔNICA DA \\ FACULDADE DE DIREITO DE FRANCA \\ www.revista.direitofranca.br \\ v. 6, n.1, dez/2012, ISSN: 1983-4225}

Nesta mesma esteira, importante transcrever o Artigo $5^{\circ}, \S 2^{\circ}$, da Lei 8.112/90, que versa sobre o Regime Jurídico dos Servidores Públicos Civis da União, das Autarquias e das fundações públicas federais:

Artigo $\mathbf{5}^{\mathbf{0}}, \mathbf{\S} \mathbf{2}^{\mathbf{0}}$. Às pessoas portadoras de deficiência é assegurado o direito de se inscrever em concurso público para provimento de cargo cujas atribuições sejam compatíveis com a deficiência de que são portadoras; para tais pessoas serão reservadas até $20 \%$ das vagas oferecidas no concurso.

Com fulcro no $\S 1^{\circ}$ do mencionado artigo, por vezes, "as atribuições do cargo podem justificar a exigência de outros requisitos estabelecidos em lei”, não se podendo alegar, em virtude de tal, prejuízo à isonomia e/ou à igualdade. Com efeito, não há se permitir que um cargo para o qual se exija velocidade e movimentos emergenciais seja ocupado por uma pessoa com deficiência física ou com mobilidade reduzida, sob pena de prejudicar os próprios princípios basilares da administração, tal qual, o da eficiência exposto no caput do artigo 37 da Carta Magna.

De outra monta, não há se negar que uma pessoa com deficiência visual ocupe um cargo de magistrado ou assemelhado. A título exemplificativo, pois não são escassos, destaca-se o Dr. Ricardo Tadeu Marques da Fonseca que, embora tenha perdido por completo a visão ainda no $3^{\circ}$ ano de Direito da Faculdade de Direito do Largo São Francisco, USP, conseguiu se formar, advogar de 1985 a 1987 e passar em um concurso para Juiz Federal do Trabalho, todavia, acabou sendo desclassificado por ser cego.

No entanto não desistiu. Colegas se mobilizaram para reverter o resultado desfavorável do concurso com um mandado de segurança, que acabou negado. Tornou-se, após, Procurador do Trabalho, sendo aprovado em $6^{\circ}$ lugar, entre cerca de 5.000 candidatos, no exame do Ministério Público do Trabalho, concluindo posteriormente mestrado e doutorado.

Em agosto de 2009, o Dr. Ricardo Tadeu Marques da Fonseca, após 18 anos na carreira de Procurador do Trabalho, foi nomeado à Justiça do Trabalho (TRT da $9^{\text {a }}$ Região - PR) pelo 


\section{REVISTA ELETRÔNICA DA \\ FACULDADE DE DIREITO DE FRANCA \\ www.revista.direitofranca.br \\ v. 6, n.1, dez/2012, ISSN: 1983-4225}

Quinto Constitucional, dispositivo previsto na Constituição Federal pelo qual o próprio Judiciário escolhe um membro do Ministério Público para fazer parte daquele Poder (Artigo 94, Constituição Federal).

Outra passagem que merece lembrança, e foi inclusive objeto de matéria do jornal Comércio da Franca, datado em 15/04/2012, é o caso do Anivaldo José de Carvalho, vulgarmente denominado como "O rei dos concursos". Anivaldo descobriu aos 18 anos que estava com a doença de Becker, uma distrofia muscular progressiva. Em nota, conta que até os 23 anos conseguiu locomover-se sozinho e concluir os cursos de Contabilidade e MBA em Controladoria. Em 2006, aos 28 anos, quando se tornou definitivamente um cadeirante, resolveu prestar concursos a fim de obter estabilidade, abandonando, até, o seu primitivo emprego.

Apesar de ter passado em inúmeros concursos, acabou abrindo mão dessas vagas para atingir o seu real objetivo: Trabalhar na área fiscal. Foi quando, então, em 2009, conseguiu aprovação no concurso de Fiscal de Rendas do Estado de São Paulo e foi chamado para fazer o curso de formação antes mesmo do resultado da perícia médica. No entanto, quando ela saiu, no meio do curso, foi reprovado; mas desta vez, resolveu tomar providências.

Atente-se que, malgrado tenha vencido a demanda ajuizada, Anivaldo teve, sem dúvidas, o seu direito violado, causando-lhe dor e sofrimento. Direito, este, que diga-se de passagem, é garantido constitucionalmente por aquele que, na prática, acaba se omitindo.

Insta consignar que os exemplos supra transcritos não são isolados. A cada dia que passa é maior a participação de pessoas com deficiência em disputas de importantes cargos públicos que, inclusive, possuem, por força constitucional, percentual de vagas para a inclusão destas pessoas no mercado de trabalho.

Cabe aqui transcrever o art. 37, VIII da Constituição Federal: "A Lei reservará percentual dos cargos e empregos públicos para as pessoas portadoras de deficiência e definirá os critérios de sua admissão."

E ainda o art. 37 e seu $\S 1^{\circ}$ do Decreto ${ }^{\circ} 3.298 / 1999$ : 


\section{REVISTA ELETRÔNICA DA \\ FACULDADE DE DIREITO DE FRANCA \\ www.revista.direitofranca.br \\ v. 6, n.1, dez/2012, ISSN: 1983-4225}

Artigo 37. Fica assegurado à pessoa portadora de deficiência o direito de se inscrever em concurso público, em igualdade de condições com os demais candidatos, para provimento de cargo cujas atribuições sejam compatíveis com a deficiência de que é portador.

$\S 1^{\circ}$ O candidato portador de deficiência, em razão da necessária igualdade de condições, concorrerá a todas as vagas, sendo reservado no mínimo o percentual de $5 \%$ em face da classificação obtida.

Ressalta-se que até mesmo às vagas reservadas, as pessoas com deficiência precisam, além de fazer o mesmo concurso, obter a nota mínima exigida elencada pela Administração Pública ao entender como qualidade suficiente para que alguém ingresse em seus quadros. Luiz Alberto primorosamente elucidou: "O importante é que os critérios sejam para todos: assim se implanta a igualdade. ",2

Por vezes, pode ocorrer que uma pessoa se inscreva dentro daquelas reservadas, por ser comprovadamente pessoa com deficiência, e acabe sendo classificado entre as primeiras colocações gerais. Luiz Alberto David Araújo, ainda a este respeito, conta com um exemplo, explanado em diversas de suas palestras, lapidarmente didático e que ilustra bem a situação. Imagine um concurso público com 100 vagas e nota mínima 7,0, das quais 90 das vagas são convencionais e 10 especiais. Verifica-se que qualquer tipo de vagas precisará de, no mínimo, média 7,0.

Suponhamos então que um tetraplégico que estudou em Harvard, e fale cinco idiomas, se inscreva em um concurso público nas vagas destinadas às pessoas com deficiência, por realmente ser, e tire nota 9,9, ficando em $1^{\circ}$ lugar geral do concurso. Suponhamos, agora, o Sr. João. O Sr. João é um paraplégico, pobre, sem condições de locomoção e sem automóveis a sua disposição. Em função disso, o Sr. João é altamente dependente dos transportes públicos; entretanto, em razão das dificuldades de colocá-lo dentro dos ônibus, que não são adaptados em sua cidade, os motoristas preferem "não o ver". Muito bem, tendo todos esses fatos em mira, elencamos que o

\footnotetext{
${ }^{2}$ Luiz Alberto David Araújo. Barrados. Pessoa com deficiência sem acessibilidade: Como cobrar, O que cobrar e de quem cobrar, p. 24.
} 


\section{REVISTA ELETRÔNICA DA \\ FACULDADE DE DIREITO DE FRANCA \\ www.revista.direitofranca.br \\ v. 6, n.1, dez/2012, ISSN: 1983-4225}

Sr. João, na prova, tirou a nota 7,01 e foi aprovado, contudo, por ter ficado na $11^{\mathrm{a}}$ posição, não foi chamado no concurso, que, por seu turno, convocou somente até a $10^{\mathrm{a}}$ colocação.

Desse modo, será que aquele $1^{\circ}$ colocado geral, que se inscrevera nas vagas preferenciais, realmente necessita estar naquelas vagas? Será que ele precisaria estar protegido pelo Estado? Neste caso, obviamente ele não precisará usar a vaga reservada, deixando esta àqueles que, não estando na lista regular dos aprovados, conseguiram tirar nota igual ou superior à mínima e está entre os primeiros da lista especial (reservada). Temos que ter em mente, dessa forma, que nem todo deficiente precisa de ajuda e de vagas reservadas. Essa idéia de que sempre precisamos ajudar é um pré-conceito, que está intimamente ligado ao prejuízo. De fato, as pessoas com deficiência sofrem algumas limitações, mas cabe ao Estado atenuar essas limitações com vistas a equipará-las ao convívio social e rateio de oportunidades.

Em que pese o brilhantismo da nossa Carta Magna, bem como da Legislação infraconstitucional, ao estabelecer inclusive um percentual mínimo, cumpre aduzir que o quantum percentual a ser fixado em edital (art. 39, Decreto 3.298/99) e o modo como as pessoas com deficiência serão chamadas, após aprovadas, ainda deixa a desejar, havendo um vácuo interpretativo nas matérias em espeque.

Importante registrar o caso da deficiente auditiva Aline Cristina da Silva, que fora aprovada em $1^{\circ}$ lugar na lista reservada de deficientes para o cargo de secretária de escola do Município de Franca, em 2010. Ocorre que, no concurso em epígrafe, que possuía 5\% de vagas reservadas às pessoas com deficiência, malgrado tenha obtido a primeira colocação na lista especial, a deficiente auditiva não fora convocada pela Prefeitura Municipal de Franca, que chamou outros 14 candidatos sem deficiência para o cargo.

Após ingressar com um mandado de segurança e pedido liminar na Justiça pleiteando a sua convocação, já que a lei prevê a reserva de, no mínimo, 5\% das vagas para os deficientes (art. 37, Decreto 3.298/99), o juiz Aurélio Miguel Pena, da $5^{\text {a }}$ Vara Cível de Franca, considerou 


\section{REVISTA ELETRÔNICA DA \\ FACULDADE DE DIREITO DE FRANCA \\ www.revista.direitofranca.br \\ v. 6, n.1, dez/2012, ISSN: 1983-4225}

injusto o critério usado pelo Município, ao convocar o deficiente somente depois que o $19^{\circ}$ aprovado é chamado, e concedeu a liminar pleiteada ${ }^{3}$.

O despacho do magistrado, ao conceder a liminar no mandado de segurança é cintilante e majestoso e acaba por ratificar a posição já sedimentada da jurisprudência, no sentido de que o chamamento deve ser feito alternadamente, uma pessoa com deficiência e uma pessoa sem deficiência, até que o percentual de 5\% se esgote, para o caso de cadastro de reserva, garantindose a igualdade, mas sem olvidar a isonomia.

Observa-se, na insigne decisão, que a tentativa de integração da pessoa com deficiência no mercado de trabalho, sendo uma luta coletiva, vem sendo intensificada, efetivando, por conseguinte, todas as diretrizes traçadas pelas leis que visam à proteção constitucional e a aplicação das leis destinadas à inclusão e acessibilidades das Pessoas com deficiência.

A exemplo do citado, transcreve-se o artigo $6^{\circ}$ do Decreto 3.298/99 que regulamenta a Lei 7.853/89 e é complementado, posteriormente, pelo Decreto 5.296/04. Vejamos.

Art. $6^{0}$. São diretrizes da Política Nacional para a integração da pessoa portadora de deficiência:

III - incluir a pessoa portadora de deficiência, respeitadas as suas peculiaridades, em todas as iniciativas governamentais relacionadas à educação, à saúde, ao trabalho (...);

$\mathbf{V}$ - ampliar as alternativas de inserção econômica da pessoa portadora de deficiência, proporcionando a ela qualificação profissional e incorporação no mercado de trabalho;

Com efeito, tratando-se de uma luta coletiva, não obstante o dever legal do Estado em fazê-lo, a obrigação quanto à inserção das pessoas com deficiência no mercado de trabalho, é obrigação de todos. Importante registrar que mesmo diante de leis rígidas e fiscalização punitiva, por meio do $M P T$, muitas empresas, assim como o faziam no período das civilizações clássicas, relutam em burlar as normas e obter meios da não contratação à pessoa com deficiência.

\footnotetext{
${ }^{3}$ http://www.gcn.net.br/jornal/index.php?codigo=146585\&codigo_categoria=4
} 


\section{REVISTA ELETRÔNICA DA \\ FACULDADE DE DIREITO DE FRANCA \\ www.revista.direitofranca.br \\ v. 6, n.1, dez/2012, ISSN: 1983-4225}

Com fulcro nesta problemática, foi criada a Lei de Cotas. A Lei de Cotas (Art. 93, Lei 8.213/91) foi um importantíssimo instrumento que traça finalidades e modalidades da inserção das pessoas com deficiência no mercado de trabalho, compelindo empresas privadas a preencherem o seu quadro com pessoas com deficiência. In verbis:

Art. 93. A empresa com 100 ou mais empregados está obrigada a preencher de $2 \%$ a $5 \%$ dos seus cargos com beneficiários reabilitados ou pessoas portadoras de deficiência, habilitadas, na seguinte proporção:

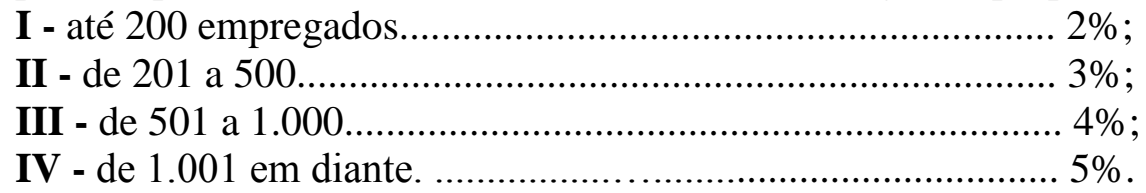

$\$ \mathbf{1}^{\mathbf{0}}$ A dispensa de trabalhador reabilitado ou de deficiente habilitado ao final de contrato por prazo determinado de mais de 90 dias, e a imotivada, no contrato por prazo indeterminado, só poderá ocorrer após a contratação de substituto de condição semelhante.

$\S \mathbf{2}^{\circ} \mathrm{O}$ Ministério do Trabalho e da Previdência Social deverá gerar estatísticas sobre o total de empregados e as vagas preenchidas por reabilitados e deficientes habilitados, fornecendo-as, quando solicitadas, aos sindicatos ou entidades representativas dos empregados.

As estatísticas, referidas no $\S 2^{\circ}$, supra, sobrevieram. Atualmente existem aproximadamente 306 mil pessoas com deficiência formalmente empregadas no Brasil, sendo que, desse total, mais de 223 mil foram contratadas em virtude da Lei de Cotas, que completou 21 anos de existência no dia 24 de julho. Em que pese nos parecer grande avanço (e realmente o foi), esse total de 306 mil carteiras assinadas ainda representam apenas 0,7\% do total de empregados formais no país. Muito pouco diante dos 46 milhões de brasileiros com algum tipo de deficiência, sendo 29 milhões em idade economicamente ativa. Além disso, se todas as empresas cumprissem a Lei de Cotas, deveríamos ter hoje no Brasil mais de 900 mil pessoas com deficiência empregadas. Ou seja, a legislação atingiu menos de um quarto de seu potencial.

Em Franca, a mero título de exemplo, conforme o último balanço divulgado pela Delegacia Regional do Trabalho, destacado pela edição de 05 de junho de 2012 do jornal 


\section{REVISTA ELETRÔNICA DA \\ FACULDADE DE DIREITO DE FRANCA \\ www.revista.direitofranca.br \\ v. 6, n.1, dez/2012, ISSN: 1983-4225}

Comércio da Franca ${ }^{4}$, das 1.903 vagas abertas para deficientes na cidade, apenas 540 estão preenchidas, restando 1.363 vagas que, seja pela falta de incentivo da categoria econômica, seja pela falta de qualificação das próprias pessoas com deficiência, estão desocupadas.

Destarte, notamos que a legislação é ampla e muita clara. E mais que um direito inerente ao ser humano, a inserção das pessoas com deficiência, no mercado de trabalho, em igualdade de oportunidades com as demais pessoas, é um dever do Estado, que, pela inteligência do Artigo 27 da Convenção sobre os Direitos das Pessoas com Deficiência, lhe incumbe uma série de ações eficazes que visam à inclusão deste grupo de pessoas que historicamente sofre com os óbices sociais de um contínuo processo de exclusão. Mais que fazer leis, é necessário aplicá-las.

- Como derradeiro comentário do direito ao trabalho, impende consignarmos a enorme importância do Ministério Público do Trabalho, que brilhantemente elimina práticas que evidenciam a discriminação nas relações de trabalho das pessoas com deficiência, além de agir no combate ao trabalho escravo, trabalho infantil, irregularidades no ambiente de trabalho que exponha a segurança e a saúde do trabalhador e outras fraudes trabalhistas, sobretudo, efetuando parcerias com órgãos e secretarias de Estado, tanto na fiscalização preventiva e conscientização como no controle repressor - por meio da ação civil pública.

\section{DO DIREITO AO TRANSPORTE}

\subsection{A Fixação dos Prazos e a Importância do Símbolo Internacional de Acesso}

O transporte é, antes de tudo, um direito instrumental, como tantos outros. Significa dizermos que sem o transporte, muitas pessoas, inclusive as com deficiência, ficariam privadas de trabalhar, de usufruir de seu lazer, de sua cultura etc. Trata-se, destarte, de um tema de suma importância não só à inclusão da pessoa com deficiência, mas também à efetivação de todos os direitos da cidadania, sem os quais, inócuo se torna inferir que o Brasil é um país democrático.

\footnotetext{
${ }^{4}$ http://www.gcn.net.br/jornal/index.php?codigo=173309\&codigo_categoria=4
} 


\section{REVISTA ELETRÔNICA DA \\ FACULDADE DE DIREITO DE FRANCA \\ www.revista.direitofranca.br \\ v. 6, n.1, dez/2012, ISSN: 1983-4225}

Por essa relevância apresentada, o direito ao transporte recebeu cognição em dois artigos na Constituição e um capítulo inteiro no Decreto 5.296/04 que, por seu turno, é enfático ao assegurar que a infra-estrutura dos meios de transporte deva ser acessível e estar disponível de forma a garantir o seu uso por pessoas com deficiência ou com mobilidade reduzida (art. 34, §ú, Decreto 5.296/04).

Dispõe a Constituição da República:

Artigo 227, § $\mathbf{2}^{\mathbf{0}}$. A lei disporá sobre normas de construção dos logradouros e dos edifícios de uso público e de fabricação de veículos de transporte coletivo, a fim de garantir acesso adequado às pessoas portadoras de deficiência.

E ainda:

Art. 244. A lei disporá sobre a adaptação dos logradouros, dos edifícios de uso público e dos veículos de transporte coletivo atualmente existentes a fim de garantir acesso adequado às pessoas portadoras de deficiência, conforme o disposto no art. $227, \S 2^{\circ}$.

Ressalta-se ser uma matéria de tanta importância que a própria Constituição Federal deu um amparo praticamente idêntico em dois dispositivos de seu corpo. Os artigos são equivalentes e resumem-se a uma única idéia: É necessária uma lei específica para regulamentar a adaptação dos transportes coletivos.

Pois bem; a lei veio. A Lei em epígrafe é a Lei 10.098/2000, que estabelece normas gerais e critérios básicos para a promoção da acessibilidade das pessoas com deficiência. A lei, entretanto, é sucinta por demais ao dispor sobre o transporte coletivo, contentando-se somente em elucidar: "Art. 16. Os veículos de transporte coletivo deverão cumprir os requisitos de acessibilidade estabelecidos nas normas técnicas específicas." (grifos acrescidos)

Assim sendo, a Lei que já era pré-requisito da Constituição Federal, prevê, ainda, um outro requisito: a existência de normas técnicas específicas. E mais, como a Lei não trouxe prazos, foi mister a elaboração de um Decreto para que o fizesse, surgindo, desse modo, o Decreto $n^{\circ} 5.296 / 04$. 


\section{REVISTA ELETRÔNICA DA FACULDADE DE DIREITO DE FRANCA \\ www.revista.direitofranca.br \\ v. 6, n.1, dez/2012, ISSN: 1983-4225}

O Decreto $\mathrm{n}^{\mathrm{o}}$ 5.296/04, ao reservar o capítulo $V$ exclusivamente à Acessibilidade aos serviços de Transportes coletivos, em seus artigos 31/46, previu também a taxatividade de prazos para a consecução de determinados comportamentos que visem à acessibilidade. Notório inferir que tal Decreto já veio tarde. Isto porque a Lei que a Constituição julgou ser necessária demorou 12 anos da promulgação da atual Constituição Federal (Lei 10.098/00), e quando sobreveio, como dito, não elencou prazos a serem respeitados, necessitando, por sua vez, do Decreto regulamentador $n^{\circ} 5.296$ que é de 2004. Ou seja, somente 16 anos após a promulgação da Carta Magna é que obtivemos êxito na simples taxatividade de prazos.

Não fosse o bastante, o Decreto ainda estipulou mais prazos para que os comportamentos fossem reajustados ao "novo" - se é que podemos chamá-lo de novo - parâmetro social. Os prazos estão contidos no artigo 38 do Decreto supra e são, por sua vez, nas palavras de Luiz Alberto David Araújo, bem generosos. Abaixo se visualiza uma tabela com o artigo colacionado e um esquema lógico-temporal para compreendermos melhor os prazos legais:

\section{PRAZOS PARA ACESSIBILIDADE NO TRANSPORTE COLETIVO RODOVIÁRIO}

12 meses (art. $38, \S 1^{\circ}$ ) 24 meses (art. 38, caput)

(03.12.2014)

Dec. 5.296, de 02/12/04 $\rightarrow$ Normas técnicas da ABNT $\rightarrow$ Novas Fabricações $\rightarrow$ Tudo acessível 120 meses $=10$ anos da publicação do Decreto $\left(\right.$ art. $\left.38, \S 3^{\circ}\right)$

Art. 38. No prazo de até 24 MESES a contar da data de edição das normas técnicas referidas no $I^{\underline{o}}$, todos os modelos e marcas de veículos de transporte coletivo rodoviário para utilização no País serão fabricados acessíveis e estarão disponíveis para integrar a frota operante, de forma a garantir o seu uso por pessoas portadoras de deficiência ou com mobilidade reduzida. $\$ \mathbf{1}^{\mathbf{0}}$ As normas técnicas para fabricação dos veículos e dos equipamentos de transporte coletivo rodoviário, de forma a torná-los acessíveis, serão elaboradas pelas instituições e entidades que compõem o Sistema Nacional de Metrologia, Normalização e Qualidade Industrial, e estarão disponíveis no prazo de ATÉ 12 MESES a contar da data da publicação deste Decreto.

$\S 2^{\underline{o}}$ A substituição da frota operante atual por veículos acessíveis, a ser feita pelas empresas concessionárias e permissionárias de transporte coletivo rodoviário, dar-se-á de forma gradativa, conforme o prazo previsto nos contratos de concessão e permissão deste serviço. $\$ 3^{o}$ A frota de veículos de transporte coletivo rodoviário e a infra-estrutura dos serviços deste transporte deverão estar totalmente acessíveis no prazo máximo de 120 MESES a contar da 


\section{REVISTA ELETRÔNICA DA \\ FACULDADE DE DIREITO DE FRANCA \\ www.revista.direitofranca.br \\ v. 6, n.1, dez/2012, ISSN: 1983-4225}

\section{data de publicacão deste Decreto.}

$\$ 4^{0}$ Os serviços de transporte coletivo rodoviário urbano devem priorizar o embarque $e$

desembarque dos usuários em nível em, pelo menos, um dos acessos do veículo

Isto posto, quanto aos meios de transporte, cabe-nos aguardar. Como visto, os novos veículos já devem ser fabricados acessíveis. Nesta senda, o ônibus interestadual, o ônibus municipal, as vans escolares já precisam sair de fábrica com as adaptações necessárias e adequadas, ao passo que as frotas já existentes têm o prazo peremptório até 03.12.2014, isto é, 120 meses da publicação do Decreto 5.296/04, pela inteligência do artigo 38, parágrafo terceiro.

Um último ponto que merece destaque foi o vitorioso advento da Lei 7.405/85, que torna obrigatória a colocação do símbolo internacional de acesso em todos os locais e serviços que permitam sua utilização por pessoas com deficiência. Impende atentarmos que a utilidade dessa lei não se restringiu tão somente a tornar obrigatório o uso do símbolo internacional de acesso, mas trouxe também consigo outros grandes avanços.

O primeiro deles foi uniformizar de forma legal, em âmbito universal, toda a simbologia de acesso, que, em norma técnica, estipulou desde os adesivos a serem colocados em banheiros até àqueles colocados no pára-brisa dos veículos.

O segundo avanço e, a nosso ver, o mais importante, foi a estipulação taxativa quanto ao uso. Notamos que só podem usar o símbolo internacional de acesso os locais que, de fato, possibilitem acesso, circulação e utilização por pessoas com deficiência. A princípio nos parece um tanto quanto óbvia tal estipulação, mas não o é.

Basta uma simples percepção da realidade em que vivemos para notarmos a comum prática de estabelecimentos, para-brisas de ônibus, recepções de hotéis e até mesmo instalações públicas, conterem o símbolo internacional de acesso sem a devida adaptação estar efetivada. Ou seja, por vezes, o símbolo se faz presente pelo simples motivo de evitar multas e penalizações de uma fiscalização que é superficial, branda e fácil de burlar, o que exige de nós, cidadãos, a contínua fiscalização a estes atos inconcebíveis. 


\section{REVISTA ELETRÔNICA DA \\ FACULDADE DE DIREITO DE FRANCA \\ www.revista.direitofranca.br \\ v. 6, n.1, dez/2012, ISSN: 1983-4225}

Veja que tudo se remonta às falhas de fiscalização, ou às chamadas falhas na competência de execução que, combinadas à falta de conscientização, resultam em uma exclusão em massa deste grupo de pessoas.

\subsection{Da Realidade Local dos Transportes Públicos e dos Logradouros}

A cidade de Franca possuía, no ano de 2011, uma população de 321.012 habitantes, segundo dados do IBGE. Demais a este fato, o município de Franca possui alto potencial rentável e produtivo, ocupando posição notória na economia brasileira, em especial por contar com diversos acordos de cooperação por empresários locais ${ }^{5}$, o que demonstra a nítida tentativa de se efetivar a aplicação da leis destinadas a inclusão e acessibilidade das pessoas com deficiência.

A cidade calçadista conta atualmente com 110 ônibus em sua frota, sendo que 60 deles, ou seja, mais que 50\%, já são adaptados e acessíveis. Outro ponto importante a ser ressaltado é a existência de 6 vans contratadas com a própria empresa encarregada do fornecimento dos transportes públicos coletivos que visam exclusivamente o transporte gratuito das pessoas com deficiência, buscando-as e deixando-as em suas residências.

Em síntese, apesar de Franca observar um rígido padrão nos transportes públicos e prédios públicos, a fiscalização e a acessibilidade nos prédios comerciais, e privados de um modo geral, bem como nas vias públicas deixam, e muito, a desejar.

Conforme se notou em algumas pesquisas de campo realizadas, a cidade de Franca, como muitas outras do Estado, ainda não demonstra maturidade e respeito quanto ao planejamento e fiscalização dessas adaptações. Impende visualizarmos que quase todos os prazos já esgotaram, em específico aqueles que ditam sobre as vias públicas e prédios particulares, como hotéis, lojas comerciais e demais estabelecimentos que insistem em não se adaptarem e acarretar a exclusão e impedir o exercício da cidadania de milhares de pessoas.

\footnotetext{
${ }^{5}$ Oportuno destacar a exímia atuação do Magazine Luíza, exemplo gratia, que, a par de sua evidente posição, firmou parceria com o Ministério Público do Trabalho e com o Senai, comprometendo-se a oferecer curso de capacitação a pessoas com deficiência que ocorrerão de agosto à dezembro de 2012.
} 


\section{REVISTA ELETRÔNICA DA FACULDADE DE DIREITO DE FRANCA \\ www.revista.direitofranca.br \\ v. 6, n.1, dez/2012, ISSN: 1983-4225}

Ressalta-se que o planejamento que uma cidade possui com relação à acessibilidade demonstra e determina com nitidez o grau de sua mobilidade urbana. Neste ponto determinado elucida-se a premente necessidade de planejamento, reconstrução e adaptação das calçadas nas vias públicas das cidades brasileiras. Constata-se que as irregularidades encontradas não interferem no viver apenas das pessoas com deficiência e dos idosos, mas também na vida de todos os cidadãos que sofrem ao tentarem transitar por uma calçada desnivelada e sem rampas de acesso (isto quando possuem calçadas...).

O Instituto Brasileiro de Geografia e Estatística - IBGE, para ilustrar ainda mais essa triste constatação, divulgou, no dia 25 de maio de 2012, o estudo "Características urbanísticas no entorno dos domicílios", baseado no Censo de 2010, que revelou que dos 95.846 domicílios de Franca, apenas 3.794 possuem rampas em suas proximidades, correspondendo a incríveis $3,96 \%$, ficando abaixo da média nacional, que aponta que as rampas estão presentes no entorno de 4,7\% dos domicílios. Demonstra claramente que Franca ainda se mostra imatura e superficial quanto à colocação de rampas de acesso e à proteção dos direitos das Pessoas com Defíciência.

A despeito da evidente ausência de planos de conscientização e incentivos, segundo coaduna o próprio Presidente da Associação dos Deficientes Físicos de Franca e Região, impende consignarmos a existência de um Plano municipal de acessibilidade, que visa exatamente atender o Decreto no 5.296/04. Este plano municipal foi organizado logo após a Secretaria de Estado dos Direitos da Pessoa com Deficiência realizar uma capacitação aos funcionários municipais em toda a região de Franca e tem diversas finalidades, dentre as quais se destaca a colocação de piso tátil no terminal de ônibus de Franca - que já está sendo colocado, segundo a pesquisa de campo - e adaptações em todos os pontos de ônibus da cidade.

Nesta esteira, há uma obra que coroa com excelência diversas pesquisas de campo realizadas com ênfase na cidade de Franca. O livro denomina-se "Cidade Amiga do Idoso: Um caminho a percorrer" e foi elaborado pelo Grupo de Estudos e Pesquisas sobre Saúde, Qualidade de Vida e Relações de Trabalho (QUAVISSS), credenciado pela UNESP-FRANCA e certificado também pelo Conselho Nacional de Desenvolvimento Científico e Tecnológico (CNPq).

Nesta senda, de bom alvitre citar a lapidar explanação que nele contém: 


\section{REVISTA ELETRÔNICA DA \\ FACULDADE DE DIREITO DE FRANCA \\ $w w w . r e v i s t a . d i r e i t o f r a n c a . b r$ \\ v. 6, n.1, dez/2012, ISSN: 1983-4225}

As esferas do governo do governo teriam como responsabilidade fazer cumprir o que está previsto nas legislações, no caso o Decreto Federal n. 5.296/2004, tornando público, através de um trabalho de conscientização, o "lugar" que essas pessoas têm garantido dentro da sociedade. ${ }^{6}$

O grupo ainda lembrou um fato importante na cidade:

(...) existe um trabalho da promotoria pública na cidade (de Franca) reivindicando o cumprimento das determinações do Decreto Federal $n^{\circ}$ 5.296/2004 de acessibilidade do município e que a Secretária de Serviços Municipais e Meio Ambiente, através da autorização de obras e reformas, somente aprove as obras que estão organizadas de acordo com a NBR 9050:2004, da Associação Brasileira de Normas Técnicas (ABNT). Assim, todas as obras precisam da aprovação do departamento de obras da prefeitura autorizando a construção ou reforma dentro dos padrões definidos pela referida norma. ${ }^{7}$

Importante asseverar que, embora tenha sido demonstrada a realidade local da cidade de Franca, interior do Estado de São Paulo, é de vital cognição sabermos que inúmeras cidades, as quais comportam a maioria, conforme visto no estudo apresentado pelo IBGE, inclusive as grandes cidades, ainda expressam uma preocupação retardada e disfuncional à proteção deste grupo de pessoas, sobretudo em relação à duas problemáticas: ao rebaixamento de guias $e$ adaptação de calçadas, suportes extremamente necessários à locomoção independente das pessoas com deficiência, e fiscalização das vagas reservadas que, em virtude da lotação dos estacionamentos, acabam sendo utilizadas por pessoas que não a necessitam.

Em sanção recentíssima, a Presidência da República publicou, após 17 anos de tramitação no Congresso Nacional, a Lei 12.587, de 3 de janeiro de 2012, que estabelece as diretrizes da Política Nacional de Mobilidade Urbana. Demais disso, no início deste ano, a Prefeitura de São Paulo, colocou em vigor a Lei Estadual no 15.442/2012, que, triplicando o valor, estipulou uma

\footnotetext{
${ }^{6}$ Cidade amiga do idoso : um caminho a percorrer / Iris Fenner Bertani ... [et.al.] (organizadoras). -Franca : UNESP - FCHS, 2011, p. 64

${ }^{7}$ Id ibid, p. 73 .
} 


\section{REVISTA ELETRÔNICA DA \\ FACULDADE DE DIREITO DE FRANCA \\ www.revista.direitofranca.br \\ v. 6, n.1, dez/2012, ISSN: 1983-4225}

multa de R \$ 300,00 por metro linear para quem não mantém o passeio público em ordem ou livre de obstáculos.

Não restam dúvidas, destarte, que em que pese haver punições notórias e severas, ainda nos deparamos com pessoas que insistem em não cumprir as leis. Quem sabe, talvez pela já elucidada falta de fiscalização. Em suma, as calçadas são o cartão postal das cidades e são elas que atraem as pessoas a utilizarem os serviços das mesmas. Corroborando nesta toada, consagra um dos sites $^{8}$ que mais se compromete com a fiscalização da acessibilidade urbana no Brasil:

Quando melhoramos 10\% dos passeios públicos que estejam em rotas estratégicas - leia-se locais de maior concentração de serviços resolvemos $80 \%$ da mobilidade de um município. Contudo, sem este planejamento, a Prefeitura tem de tomar outras medidas, como a aplicação de multas, responsável por gerar mais reclamações que soluções realmente eficientes.

E, ainda sim, o trabalho de fiscalização, que é de obrigação do Executivo, só ocorre após denúncias dos pedestres. Sem essas reclamações, que chegam, principalmente, por meio do site da Prefeitura ou diretamente nas subprefeituras, a fiscalização não é feita. É aí que voltamos a um ponto crucial neste ciclo: a participação do cidadão.

(...)

As calçadas são o cartão postal das cidades. Elas não só deflagram o planejamento urbano de bons gestores, como as atitudes de uma população consciente e inclusiva. Promover estas frentes tem de fazer parte da nossa luta diária por uma cidade mais acolhedora.

Outra participação reluzente na defesa da acessibilidade urbana às pessoas com deficiência é a célebre atuação da atual Deputada Federal Mara Gabrilli, eleita em 2010 com 160.138 votos. A insigne parlamentar, ex-vereadora da Câmara municipal de São Paulo e primeira titular da Secretaria Municipal da Pessoa com Deficiência e Mobilidade Reduzida da Prefeitura de São Paulo, por meio de seu site, disponibiliza diversos projetos de lei e trabalhos de excelência, demonstrando ainda a sua efetiva participação no Congresso Nacional enquanto

\footnotetext{
${ }^{8}$ www.mobilize.org.br
} 


\section{REVISTA ELETRÔNICA DA \\ FACULDADE DE DIREITO DE FRANCA \\ $w w w . r e v i s t a . d i r e i t o f r a n c a . b r$ \\ v. 6, n.1, dez/2012, ISSN: 1983-4225}

pessoa com deficiência física. Um exemplo do citado, dentre inúmeros, é a cartilha "Olhe a Paulista, Avenida Universal" que dispõe, com acerto, como a Avenida Paulista tem sido objeto de referência à acessibilidade em todo o País.

Em se tratando de vagas especiais o problema é ainda mais contundente. Em consonância aos números da Companhia de Engenharia de Tráfego - CET, só na cidade de São Paulo, em 2011, foram aplicadas 9.807 multas em uma cidade que possuí 1.038 vagas reservadas às pessoas com deficiência. A princípio parece uma fiscalização atuante, mas se pensarmos que a maior parte dessas vagas são diariamente ocupadas por quem não as necessitam, acabamos por concluir que a fiscalização ainda se mostra inócua e ineficaz. O descumprimento dessas vagas reservadas acarreta, além da multa, a perda de três pontos na Carteira de Habilitação e Remoção do veículo.

É verdade que a fiscalização se faz necessária também pelos cidadãos. Ocorre que, por vezes, tais advertências por cidadãos comuns acabam gerando divergências e discussões que resultam em agressões. Caso semelhante, muito repercutido, ocorreu em São José dos Campos, estado de São Paulo, em 20/01/2011, quando o Delegado Damásio Marino, que havia estacionado em uma vaga reservada, agrediu, com a sua arma, um cadeirante que foi tirar satisfação com a autoridade policial.

Processado por injúria, ameaça, abuso de autoridade - por utilizar a arma além do exercício legal da profissão - e lesão corporal, o Delegado foi absolvido pelos três primeiros crimes, sendo condenado a três meses em regime aberto tão somente pela lesão, que foi constatada por exame pericial. Três meses, estes, convertidos em prestação de serviço comunitário por um ano 9 .

Outro óbice ao respeito às vagas especiais localiza-se no próprio planejamento e criação de vagas comuns de estacionamento. Em nota divulgada em 07/07/2012, o Jornal Comércio da Franca, em entrevista com o secretário de Segurança e Cidadania, relatou que Franca conta hoje com cerca de 203.466 veículos. Não obstante esse aumento tenha representado $68 \%$ em 7 anos, a

${ }^{9}$ http://noticias.terra.com.br/brasil/noticias/0,,OI5300083-EI5030,00-

Delegado+que+agrediu+cadeirante+e+condenado+a+prestar+servicos.html 


\section{REVISTA ELETRÔNICA DA \\ FACULDADE DE DIREITO DE FRANCA \\ www.revista.direitofranca.br \\ v. 6, n.1, dez/2012, ISSN: 1983-4225}

Prefeitura não aumentou o número de vagas que está, desde 2005, limitado a 700 vagas em sua totalidade, sendo 40 vagas reservadas para idosos e 30 para pessoas com deficiência.

É preciso, dessa feita, que haja um processo mais acentuado de conscientização da população no sentido de expor a todos - deficientes ou não - que as "pessoas com deficiência são, antes de mais nada, pessoas "10 e que, por esta ratio, possuem todos os direitos inerentes e assegurados à pessoa humana, dentre os quais um se destaca: o direito de ir e vir, e permanecer, em qualquer lugar, sem que necessite ou dependa de qualquer auxílio ou solidariedade de quem quer que seja. Lembrando que, mais importante que reclamar, é PARTICIPAR.

\section{CONSIDERAÇÕES FINAIS}

Neste breve estudo apresentado, fez-se por finalidade apresentar a discrepância entre a legislação vigente e a efetiva inclusão das pessoas com deficiência em nossa sociedade. Como sabido, as pessoas que apresentam qualquer deficiência representam uma soma inacreditável de aproximadamente 45,6 milhões. São, desse modo, aproximadamente $24 \%$ da população brasileira que não estão nos teatros, não estão nos cinemas, não estão nas bibliotecas por conta de algum motivo. E foi exatamente o costume de não os ver, no mínimo na proporção apontada, nos lugares, que nos empenhamos em buscar as verdades.

Como já exaustivamente advertido, embora o Brasil esteja começando a expressar nítida preocupação, atualmente se nota que não mais é o limite individual que determina as limitações das pessoas, e sim as barreiras que ainda se encontram nos serviços, nos espaços físicos, na comunicação e na informação.

Coerente seria apresentar uma possível solução neste momento, mas se tratando de um problema tão incisivo como o é, difícil se faz tal constatação. Conseguimos, no entanto, distinguir a ausência de três pilastras cruciais que ainda atravancam o brilhante potencial brasileiro: a

\footnotetext{
${ }^{10}$ Trecho que segue encartado na Apresentação da Convenção sobre os Direitos das Pessoas com Deficiência
} 


\section{REVISTA ELETRÔNICA DA \\ FACULDADE DE DIREITO DE FRANCA \\ www.revista.direitofranca.br \\ v. 6, n.1, dez/2012, ISSN: 1983-4225}

ausência de fiscalização, de conscientização e de respeito. Com efeito, ao longo de todo o trabalho houve a tentativa de demonstrar a real importância que cada uma dessas palavras traduz ao quadro social, de modo que somente com uma campanha de conscientização intensiva e com uma fiscalização punitiva, não só realizada pelos entes estatais, mas também por todos os cidadãos, conseguiríamos simbolizar o respeito e a reeducação necessários à proteção constitucional e aplicação das leis destinadas à inclusão e acessibilidade das pessoas com deficiência.

Somente com estes três conceitos na prática e lembrando que quando a dignidade de uma pessoa com deficiência é ferida, a dignidade de todos, de um modo geral, é ferida, contemplaremos a inteligência do imensurável Artigo $3^{\circ}$, da Constituição Federal, que consiste em promover o bem de TODOS independentemente de raça, cor, sexo ou quaisquer outras formas de discriminação social.

\section{REFERÊNCIAS BIBLIOGRÁFICAS}

ARAÚJO, Luiz Alberto David. Barrados. Pessoa com deficiência sem acessibilidade: Como cobrar, O que cobrar e de quem cobrar. Petrópolis: Ed. KBR, 2011.

BERTANI, Iris Fenner et al. Grupo QUAVISSS. Cidade Amiga do Idoso: Um caminho a percorrer. Franca: Cultura Acadêmica, 2011.

CORRER, R. Deficiência e Inclusão Social: construindo uma nova sociedade. EDUSC: 2003. 